\title{
MODEL INTERAKSI MULTI KULTUR DALAM RUANG VIRTUAL WHATSAPP: SILATURAHMI, KONFLIK, LEAVE GROUP
}

\author{
Aji Aditra Perdana ${ }^{1}$, Irwansyah ${ }^{2}$ \\ ${ }^{1}$ Universitas Pelita Harapan \\ Jl. MH. Thamrin Boulevard 1100, Klp. Dua, Karawaci, Tangerang, Banten 158111 \\ ${ }^{2}$ Universitas Indonesia Kampus Depok \\ Departemen Ilmu Komunikasi Fakultas Ilmu Sosial dan Ilmu Politik \\ Telp: 08557282828 Email: adjieperdana@gmail.com
}

\begin{abstract}
WhatsApp application allows each individual to interact free from the boundaries of space and time, but many problems in interaction appears. This study aims to find an interaction model in communicating via WhatsApp to Telco industry workers in Jakarta. The research is carried out qualitatively with observation and interview with WhatsApp users. The result shows that the multi-cultural interaction model in virtual space can be interwoven well if the user has a good literacy in communicating through WhatsApp. This study can provide learning to each individual that interacts on WhatsApp involving individuals in multiple cultures. Messages sent to virtual space can cause multiple perceptions because members are coming from different backgrounds. This study recommends the existence of multi-cultural literacy.
\end{abstract}

Keywords: WhatsApp, interaction, multi culture.

\begin{abstract}
ABSTRAK
Aplikasi WhatsApp memungkinkan setiap individu untuk berinteraksi secara bebas dari batas ruang dan waktu, tetapi banyak masalah dalam interaksi yang muncul. Penelitian ini bertujuan untuk menemukan model interaksi dalam berkomunikasi melalui WhatsApp kepada pekerja industri Telco di Jakarta. Penelitian ini dilakukan secara kualitatif dengan observasi dan wawancara dengan pengguna WhatsApp. Hasilnya menunjukkan bahwa model interaksi multi-budaya di ruang virtual dapat terjalin dengan baik jika pengguna memiliki kemampuan baca tulis yang baik dalam berkomunikasi melalui WhatsApp. Studi ini dapat memberikan pembelajaran bagi setiap individu yang berinteraksi di WhatsApp yang melibatkan individu dalam berbagai budaya. Pesan yang dikirim ke ruang virtual dapat menyebabkan banyak persepsi karena anggota berasal dari latar belakang yang berbeda. Studi ini merekomendasikan keberadaan literasi multi-budaya.
\end{abstract}

Kata kunci: WhatsApp, interaksi, multi kultur.

\section{Pendahuluan}

Cara manusia berinteraksi dengan individu lain mengalami kemajuan signifikan sejak kemunculan teknologi digital. Kini manusia bisa berkomunikasi tanpa dibatasi dengan ruang dan waktu melalui media berupa smartphone dan akses internet. Salah satu yang paling fenomenal adalah penggunaan aplikasi smartphone untuk berkirim pesan, WhatsApp. WhatsApp didirikan oleh Jan
Koum dan Brian Acton, dua rekan kerja di Yahoo. Koum merupakan imigran asal Ukraina yang pindah bersama ibunya ke Amerika Serikat. Pertemuannya dengan Brian Acton membuatnya bergabung dengan Yahoo, dan bekerja selama sembilan tahun (Kompas. com, 2014).

Kesamaan pemikiran Koum dan Acton tentang pemasangan iklan dan logo di halaman situs membuat mereka sepakat untuk hengkang 
dari Yahoo. Mereka bertekad membangun sebuah aplikasi yang dapat membantu manusia untuk berkomunikasi tanpa adanya gangguan dari iklan yang membuat pengguna tidak nyaman (Kompas.com, 2014). WhatsApp Inc berdiri pada tanggal 29 Februari 2009 di California. Produk pertamanya WhatsApp messenger, sebuah aplikasi lintas platform yang menawarkan layanan berkirim pesan tanpa harus membayar biaya. Nama WhatsApp sendiri terinspirasi dari frasa "what's up!" yang berarti "ada apa?!" atau "apa kabar?!" (WhatsApp, 2015).

Layanan yang ditawarkan WhatsApp disambut baik oleh masyarakat di seluruh dunia (WhatsApp, 2015). Terbukti dengan pengguna lebih dari satu milyar orang di 180 negara, WhatsApp menjadi aplikasi berkirim pesan favorit sebagian besar pengguna smartphone (Similarweb.com, 2017). Dengan performa yang memukau di dunia digital, WhatsApp memikat para investor untuk dapat memiliki sahamnya. Pada 2014 WhatsApp akhirnya diakuisisi dan bergabung dengan facebook (WhatsApp, 2015). Dengan nilai akuisisi senilai 19 milyar dolar (Wired.com, 2018). WhatsApp menjadi aplikasi nomor satu yang paling sering digunakan, oleh pengguna smartphone Android di Indonesia (Similarweb. com, 2017). Aplikasi WhatsApp sudah mulai menggantikan peran layanan voice dan Short Messaging Service (SMS). Layanan tersebut didukung data yang disediakan oleh operator telekomunikasi, salah satunya Indosat Ooredoo.

Perusahaan operator telekomunikasi yang menyediakan layanan voice dan SMS merasa kehadiran WhatsApp sebagai disruption yang cukup memberikan pergeseran gaya penggunaan layanan komunikasi masyarakat. Dengan hadirnya internet, pengguna layanan telekomunikasi lebih memilih aplikasi yang dapat menghemat biaya pemakaian produk telekomunikasi untuk melakukan percakapan

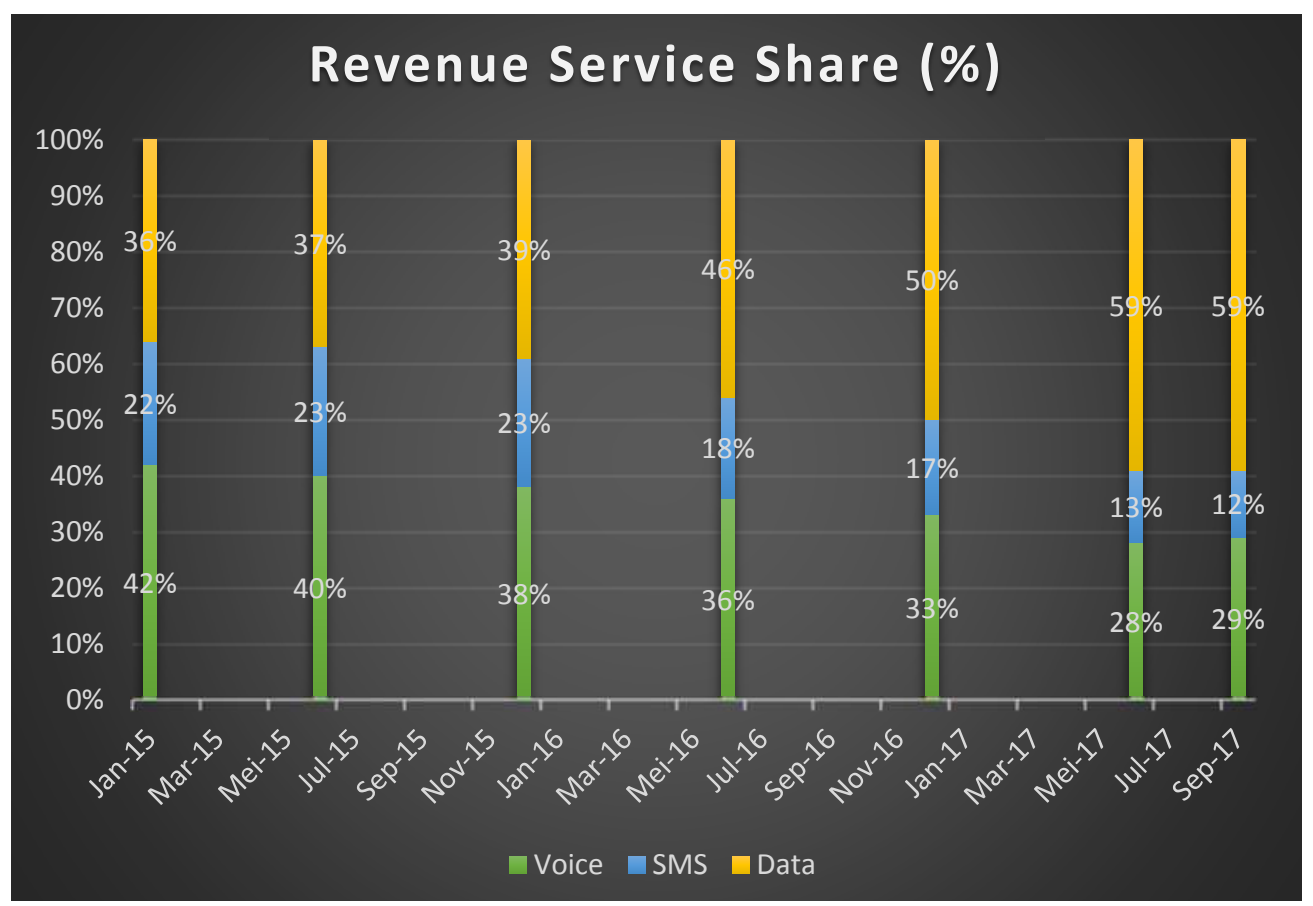

Gambar 1. Revenue Service Share Indosat Ooredoo Regional Jabotabek Sumber: Dokumen Indosat Ooredoo 
maupun komunikasi (Nasrudin, 2017). Didin Nasrudin, Division Head Regional Commercial Operation Indosat Ooredoo juga mengungkapkan tren penggunaan layanan voice dan SMS berangsur turun sejak tahun 2015. Masyarakat berpindah ke layanan data yang memungkinkan melakukan berbagai aktivitas, seperti berkirim pesan teks, berkirim pesan suara, atau bahkan melakukan video call dengan platform WhatsApp.

Gambar 1 menyajikan data revenue share dari Indosat Ooredoo Regional Jabotabek yang melayani 15 juta pelanggan. Kota-kota yang menjadi acuan pada lingkup Jabotabek saja atau uraian lokasi (Nasrudin, 2017). Pada Januari 2015, revenue share yang didapat dari layanan voice mencapai 42\%, namun sampai tahun 2016 makin turun dan akhirnya hanya mencapai $29 \%$ di September 2017.

Berbeda dengan layanan data yang semula hanya 36\% di Januari 2015, perlahan naik dengan sangat drastis menggerus layanan voice dan SMS. Dalam jangka waktu kurang dari tiga tahun, revenue layanan data meningkat 23\% hingga mencapai 59\% di bulan September 2017. Hal ini tentunya tidak bisa dibilang baik untuk Indosat Ooredoo karena pada dasarnya hal ini menggerus potensi revenue yang bisa didapatkan dari layanan voice dan SMS. Karena revenue yang didapatkan dari layanan voice cukup besar berkontribusi untuk Indosat Ooredoo (Nasrudin, 2017).

Penggunaan media komunikasi digital seperti WhatsApp tidak sejalan dengan literasi komunikasi multi kultur yang dimiliki pengguna. Literasi komunikasi kultur yang dimaksud adalah bagaimana pengguna memiliki kepandaian serta kecakapan dalam perbedaan yang dimiliki setiap individu. Komunikasi multi kultur sangat dipengaruhi oleh konsep diri, tindakan, interaksi sosial, dan juga aksi kolektif. Sebagaimana dijelaskan oleh Blummer dalam teori interaksi simbolik, yang dikutip oleh Griffin (Griffin, 2012). Setiap manusia merupakan organisme yang sadar akan dirinya, manusia mampu memandang dirinya sebagai objek pikirannya, bergaul atau berinteraksi dengan diri sendiri (Silvana, 2013). Tindakan yang dilakukan manusia juga dibentuk melalui proses konstruksi diri. Sebelum bertindak, manusia harus menentukan tujuan, menggambarkan arah tingkah lakunya.

Dijelaskan oleh Soeprapto, teori interaksi simbolik memusatkan perhatiannya pada interaksi antara individu dan kelompok, dimana setiap individu berinteraksi dengan menggunakan simbolsimbol, yang didalamnya berisi tandatanda. Suatu kata tidak memiliki makna yang melekat, melainkan hanya sebuah bunyi, dan akan memiliki makna bila suatu kelompok sependapat bahwa bunyi tersebut mengandung suatu arti khusus, sebagaimana dikutip oleh Silvana (Silvana, 2013). Kelompok-kelompok individu diklasifikasikan oleh etnis, agama, geografis, bahasa, dan lainnya. Mereka mempunyai ciri khas yang ditentukan oleh kelompok itu sendiri kemudian membentuk polanya. Perbedaan dalam masyarakat dapat berbaur apabila terjadi dalam kurun waktu yang cukup lama, sehingga akhirnya terbentuk sistem sosial dalam masyarakat (Silvana, 2013). 
Sebagaimana disebutkan David Hakken, yang dikutip oleh Rulli Nasrullah (Nasrullah, 2017), isu kunci etnografi virtual di internet adalah (1) karakteristik dasar dari entitas yang berada dan membentuk budaya virtual di ruang siber, identitas diri yang dikonstruk oleh entitas, relasi sosial, dan juga struktur ekonomi politik yang berada di suang siber, (2) identitas diri yang dikonstruk oleh entitas, (3) level mikro, konstruksi relasi sosial yang erat dan dibangun oleh entitas itu sendiri, (4) level meso, relasi sosial yang lebih kompleks, seperti komunitas, regional, atau relasi antar masyarakat, (5) macro social relations atau relasi sosial pada level makro, seperti nasional atau antarnegara, (6) struktur dalam ekonomi politik yang berada di ruang siber dan diproduksi maupun direproduksi oleh entitas dengan melibatkan aturan/batasan tertentu di dalamnya.

Kecakapan komunikasi multi kultur sangat diperlukan dalam komunikasi yang termediasi komputer dengan jaringan internet atau Computer Mediated Communication (CMC). Hal ini bisa menaikkan level bahasa yang sebelumnya simetris menjadi asimetris. Dalam komunikasi di ruang virtual memberikan konsep bahasa yang berbeda dengan komunikasi tatap muka, baik secara simbol atau tanda maupun pemaknaan yang terkandung di dalamnya (Silvana, 2013). Ekspresi yang disampaikan dalam ruang virtual dapat bermakna nonlinear, sebagaimana makna yang ada dalam komunikasi tatap muka. Misalnya menyampaikan kalimat "kamu lucu ya" jika hanya berupa teks, dapat bermakna macammacam. Dapat diartikan lucu dalam arti komedi, lucu dalam arti cantik, atau lucu bernada sindiran karena tersinggung dengan kalimat yang disampaikan sebelumnya.

Literasi yang sangat dibutuhkan adalah bagaimana pengguna komunikasi yang termediasi dalam ruang virtual dapat memilah pesan yang diterima, dan tidak memaknai seperti yang tertulis secara lisan. Perbedaan usia, etnis, agama, dan geografis menyebabkan cara berkomunikasi akan jauh berbeda. Menunggu sistem sosial terbentuk dalam ruang virtual membutuhkan waktu yang cukup lama. Sementara itu perkembangan teknologi yang sangat cepat akan memunculkan teknologi yang baru lagi sebelum sistem sosial terbentuk. WhatsApp digunakan untuk menjalin tali silaturahmi antara teman, keluarga, bahkan hubungan rekan kerja. Ftur WhatsApp group mempermudah menyatukan banyak individu dalam satu ruang virtual. Pendekatan teori yang digunakan untuk menganalisis fenomena WhatsApp adalah teori Computer-Mediated Communication (CMC). Komunikasi antar manusia dilakukan dengan dua alat yang berbeda (Walther, 1996). Komunikasi dilakukan oleh manusia dengan medium berupa alat computer-mediated format (instant messaging, social network, email, dan online forums). Dengan media komputer, maka komunikasi dapat menembus ruang dan waktu.

Terdapat dua bentuk komunikasi, yaitu synchronous (real time) dan asynchronous (delay). Bentuk synchronous dapat dijumpai pada dua orang yang berkomunikasi langsung face to face. Asynchronous ditemukan pada Computer-Mediated Communication, seperti chat room dan video 
message, dimana memerlukan waktu untuk memberikan feedback (Walther, 1996). Proses komunikasi juga dapat menjadi interpersonal dalam Computer-Mediated Communication. Hal ini terjadi ketika pengguna mulai memberikan waktu untuk dapat bertukar pesan, membangun kesan, dan bahkan membandingkan nilai. CMC menjadi tidak kalah personalnya dengan face to face communication, namun $\mathrm{CMC}$ butuh waktu lebih lama agar sampai kepada proses tersebut (Walther, 1996).

Pada saat pengguna mulai bisa menciptakan kesan dan mengelola hubungan dengan lebih positif, dibandingkan face to face communication, tanpa sadar pengguna sudah berada dalam tahap hyperpersonal (Walther, 1996). Avatar yang dipilih menjadi lebih selektif, pemilihan diksi yang dipikirkan matang, membangun citra sebagai orang lain yang dianggap 'idola', dan akhirnya menjadi orang yang berbeda dengan kepribadian sebenarnya. Keseharian pada beberapa individu sangat pandai dalam bersosialisasi. Mereka memiliki kompetensi sosial yang sangat baik. Hal ini tidak bisa dilakukan hanya dengan berkomunikasi secara verbal atau hanya mengirimkan pesan berupa kata-kata, namun diperlukan kemampuan untuk dapat menyampaikan pesan dengan cara nonverbal (Knapp \& Hall, 2006)

Pesan nonverbal dapat diartikan sebagai suatu pesan yang ingin dikirimkan menggunakan simbol-simbol yang terdapat dalam tubuh. Misalnya intonasi suara, gerakan tangan, ekspresi wajah, dan juga masih banyak lagi. Hal ini melengkapi pesan yang dikirimkan melalui kata-kata yang membentuk sebuah kalimat (Knapp \& Hall, 1997). Nonverbal sinyal adalah bagian penting dalam semua usaha manusia dalam berkomunikasi, dapat mengerti dan menggunakan nonverbal sinyal adalah aspek krusial untuk kesuksesan manusia di hampir semua interaksi sosial yang dialami (Knapp \& Hall, 1997).

Untuk melakukan komunikasi nonverbal maka diperlukan sebuah bahasa universal agar dapat dimengerti oleh setiap individu yang menggunakan $\mathrm{CMC}$ sebagai pilihan cara berkomunikasi dengan individu lain yang berjauhan jaraknya. Teori interaksi simbolik dapat digunakan untuk meneliti fenomena pemaknaan pesan yang terjadi dalam ruang virtual WhatsApp. Sebuah pesan tidak bermakna, manusialah yang memberikan makna. Penyematan makna pada pesan pada setiap individu bisa berbeda, tergantung kepada referensi dan pengalaman masing-masing individu (Griffin, 2012)

Pada teori interaksi simbolik, terdapat konsep the self yang memiliki dua variabel penting yaitu $I$ dan $M e$. $I$ adalah karakter bawaan yang dimiliki oleh setiap individu, spontan, dan sulit diprediksi. Sedangkan $M e$ adalah karakter diri yang dibentuk dari lingkungan diluar, hasil reaksi interaksi dengan orang lain pada individu (Griffin, 2012). Menurut Benedictus A. Simangunsong dalam penelitiannya mengungkapkan, "Terjadi peralihan tempat aktivitas manusia yang awalnya dibatasi oleh batas geografis maupun batas keberadaan manusia secara langsung diganti dengan ketiadaan batas secara geografis maupun keberadaan manusia melalui medium. Sehingga seringkali individu 
tidak mengetahui siapa lawan bicaranya, sehingga konsep ruang virtual dalam hal ini bisa dikatakan dalam terminologi mediated communication" (Simangunsong, 2016:67).

Manusia mulai mereduksi syarat-syarat yang dibutuhkan, untuk tercapainya proses pengiriman pesan yang efektif. Teknologi audio visual misalnya, membutuhkan dua panca indera agar bisa menerima pesan dengan baik. Lalu bagaimana mungkin aplikasi WhatsApp, sebuah aplikasi berkirim pesan berupa tulisan, gambar, video, bahkan melakukan panggilan suara dan video menjadi sangat populer dan digunakan banyak orang.

Penelitian yang dilakukan oleh Dewi K. Soedarsono dan Roro Retno Wulan memaparkan model komunikasi remaja melalui media internet. Hasilnya menunjukkan bahwa tidak semua individu yang tergabung dalam satu ruang virtual memiliki pemikiran yang seirama. Jika sudah mulai memiliki ketidaksukaan individu akan memilih membentuk ruang virtual baru dengan anggota yang memiliki pemikiran sama (Soedarsono, 2017). Rifqi Fauzi dalam penelitiannya menemukan bahwa dengan munculnya teknologi smartphone, menjadikan komunikasi tatap muka mulai ditinggalkan. Hal ini disebabkan kemudahan yang ditawarkan oleh teknologi digital. Masyarakat digital natives yang lahir setelah tahun 1980 dan sudah menguasai teknologi sosial digital memiliki akses untuk saling terhubung secara terus menerus. Generasi ini mampu mengubah dan mendesain ulang informasi yang di dapatkan, untuk kemudian di tampilkan kembali dalam media digital (Fauzi, 2017).
Menurut Afina Amna, WhatsApp mengubah konsep jarak sosial dalam masyarakat. Sebuah grup WhatsApp masyarakat seolah berhak untuk menyebarkan informasi, serta mengomentari tanpa rasa takut pada jarak sosial di dunia nyata. Karena terhubung hanya melalui teks, rasa sungkan akan dapat lebih berkurang dibandingkan berbicara langsung (Amna, 2018). Oemar Madri Bafadhal melakukan penelitian tentang bagaimana masyarakat melakukan konsumsi berita melalui grup WhatsApp. Studi itu dilakukan pada suatu kelompok homogen. Oemar menemukan bahwa informan yang dipilih juga mengkonsumsi berita melalui media konvensional namun lebih cenderung percaya pada informasi yang dibagikan melalui grup WhatsApp pengajian miliknya. Alasannya di dalamnya berisi orang-orang yang dapat dipercaya dan memiliki satu pandangan yang sama (Bafadhal, 2017).

Dari beberapa penelitian yang sudah dilakukan, penelitian ini menemukan gap. Melalui interaksi yang dilakukan di dalam ruang virtual, sebagian besar dilakukan oleh komunitas heterogen yang 'terjebak' dalam satu kesamaan entitas. Bisa memiliki kesamaan sekolah, lingkungan tempat tinggal, tempat bekerja, proyek lintas perusahaan, atau bahkan kelompok kesamaan hobi. Penelitian ini bertujuan menemukan model interaksi multi kultur dalam ruang virtual WhatsApp pada pekerja industri telekomunikasi di Jakarta. Dengan demikian individu dapat menciptakan interaksi yang positif pada kelompok multi kulturdi ruang virtual. 


\section{Metode Penelitian}

Penelitian ini menggunakan metode kualitatif dengan pendekatan fenomenologi. Pendekatan fenomenologi tidak berangkat dari hipotesa, namun melihat kenyataankenyataan yang muncul dalam proses penelitian. Pengumpulan data dilakukan melalui observasi interaksi dalam group chat dan interaksi antarpribadi menggunakan WhatsApp, serta wawancara yang dilakukan kepada enam orang informan. Kriteria pemilihan informan adalah pelaku industri telekomunikasi, pengguna aktif WhatsApp, dan juga memiliki kordinasi dengan $>100$ orang menggunakan WhatsApp. Dari kriteria ini, terpilih 6 orang yang berasal dari perusahaan penyedia layanan telekomunikasi terbesar di Indonesia yaitu Telkomsel, Indosat Ooredoo, dan XL Axiata.

Pengumpulan data dilakukan melalui observasi dan wawancara semi terstruktur seperti berdiskusi santai, informal style namun serius. Wawancara semi terstruktur digunakan karena bisa mendorong komunikasi dua arah dan bisa mengkonfirmasi apa yang sudah diketahui dan memberi kesempatan untuk belajar. Sehingga dapat dilakukan cross check dengan apa yang peneliti lihat di lapangan.
Selain itu juga dapat mendorong informan untuk menghubungkan pengalaman dan perspektif yang relevan dengan masalah kepentingan mereka. Analisis kualitatif teks sering dilengkapi dengan sumber informasi lain untuk memenuhi prinsip triangulasi dan meningkatkan kepercayaan terhadap validitas kesimpulan penelitian.

Wawancara dilakukan pada periode 13-27 November 2017. Pertanyaan yang disampaikan terkait penggunaan aplikasi WhatsApp, interaksi sosial dengan teman, penggunaan WhatsApp untuk pekerjaan, dan pilihan aplikasi selain WhatsApp.

\section{Hasil Penelitian dan Pembahasan}

Penelitian ini mencoba menemukan konflik yang terjadi pada komunikasi di ruang virtual WhatsApp. Dari pengamatan langsung karena peneliti juga berada di dalam sebuah group chat WhatsApp, peneliti dapat merumuskan sebuah model interaksi multi kultur dalam komunikasi ruang virtual, group chat WhatsApp. Menurut informan penelitian, konflik yang paling sering terjadi adalah mispersepsi dalam memaknai sebuah pesan. Kalimat yang seharusnya hanya sebuah pertanyaan bisa dimaknai menjadi pernyataan yang menyinggung.

TabeL 1. Sampel Penelitian

\begin{tabular}{lllc}
\hline No & Name & \multicolumn{1}{c}{ Position } & Length of Interview \\
\hline 1 & Sonny Hadi Bowo & Digital Expansion Telkomsel & 14:34 Minutes \\
2 & Didin Nasrudin & Regional Commercial Operation & $10: 04$ Minutes \\
& & Indosat Ooredoo & \\
3 & Indra Raharjo & OTT \& VAS Analyst XL Axiata & $13: 27$ Minutes \\
4 & Elly Meliawati & Marketing Communication & $15: 20$ Minutes \\
& & Manager Indosat Ooredoo & \\
5 & Annisa Widyotami & Brand Comm Indosat Ooredoo & $12: 35$ Minutes \\
6 & Hayatin Nusur & Account Manager Telkomsel & $10: 05$ Minutes \\
\hline
\end{tabular}


"Jika seseorang mengirimkan pesan di group chat WhatsApp tanpa disertai dengan emoticon atau kata tambahan yang bisa menggambarkan intonasi, maka yang terjadi adalah kesalahpahaman pemaknaan kata. Kalimat 'biasa aja' bisa dimaknai dengan berbagai arti, biasa aja yang berarti benartidak ada apa-apa, biasa aja yang berarti instruksi untuk tidak usah marah-marah, atau juga biasa aja yang berarti tidak bagus atau kurang menarik. Bahkan kalimat 'elo gendutan ya' karena kelupaan kasih tanda tanya dan emoticon, gue dianggap menghina fisik orang!" (Sony Hadi Bowo, 2017)

Mispersepsi dalam group chat ini dapat terjadi karena perbedaan referensi setiap invididu. Di dalam ruang virtual berisi individu multi kultur, suatu teks yang dianggap candaan oleh sebagian group member dapat berarti ejekan atau hinaan pada sebagian individu lain di dalam group. Dalam teori interaksi simbolik ini adalah konsep 'I', dimana kepribadian dibentuk dari dalam diri individu sendiri. Jika individu merasa pesan yang disampaikan tidak cocok dengan dirinya maka tidak akan masuk untuk membentuk 'Me' dan cenderung akan ditolak. Sebuah kelompok di ruang virtual tidak boleh memaksakan nilai suatu pesan baik atau buruk kepada individu lain.

"Jika sudah terjadi percikan konflik dalam suatu group chat, sekelompok member akan membentuk group chat baru dengan member yang memiliki kesamaan 'frekuensi'. Jika seorang individu sudah merasa tersinggung, maka akan memilih untuk leave group chat." (Sony Hadi Bowo, 2017)

\section{Dalam teori Computer-Mediated}

Communication, proses komunikasi yang termediasi dapat berubah menjadi interpersonal ketika pengguna mulai memberikan waktu berkirim pesan, membangun kesan, dan membandingkan nilai. Komunikasi yang tadinya hanya sebatas group chat akan menjadi personal chat, dan membandingkan anggota kelompok yang tidak sependapat dengan mereka di dalam ruang virtual. Kesamaan inilah yang akan membangun hubungan menjadi lebih positif. Hubungan yang positif dapat membentuk kelompok yang memiliki persamaan pandangan.

"WhatsApp memberikan kemudahan pada setiap kordinasi pekerjaan, yang melibatkan banyak tim dan lintas lokasi. Jika seseorang berada di Jakarta namun memiliki banyak tim dari berbagai kota, maka akan jadi sangat penting untuk mendapatkan informasi ter-update dari setiap anggota, baik berupa foto atau teks berita kegiatan." (Didin Nasrudin, 2017)

"Di era digital seperti saat ini, informasi menjadi sangat penting di setiap menitnya, bukan saatnya menunggu kabar sampai berjam-jam. Karena dengan WhatsApp sifatnya bisa menunggu dan dapat dibaca beberapa saat kemudian, jika penerima sedang melakukan hal lain, misalnya meeting atau sedang berbicara dengan orang lain. Hal yang belum dapat dilakukan oleh teknologi telpon, dimana jika sedang menerima telpon dari orang lain, maka seseorang tidak bisa menerima telpon masuk kembali. Jadi baik penelepon harus kembali meluangkan waktunya untuk melakukan panggilan kembali, agar pesannya bisa tersampaikan. Berapa banyak waktu yang terbuang dan aktifitas terhenti, untuk melakukan panggilan telpon yang tidak tersambung." (Indra Raharjo, 2017)

\section{Sony menjelaskan fitur group chat} dalam WhatsApp sangat membantu aktivitas penunjang pekerjaan, dan juga tempat berkomunikasi dengan berbagai macam latar belakang hubungan setiap individu. Ada yang membentuk group chat untuk diisi anggota keluarga, teman satu kelas, reuni sekolah, dan rekan dalam satu departemen di kantor. Bahkan kini di setiap proyek terbaru dalam pekerjaan harus memiliki group chat demi kemudahan kordinasi dan juga pengiriman update foto yang lebih cepat. 
Pada sebuah group chat WhatsApp, berbagai individu multi kultur dikumpulkan dalam satu ruang virtual. Setiap terjadinya reuni sekolah, kuliah, silaturahmi keluarga, member kelas, proyek pekerjaan terbaru, dan juga komunitas lingkungan tempat tinggal, sebuah kelompok individu akan membuat satu group chat menggunakan WhatsApp. Hal ini dimungkinkan karena grup WhatsApp memiliki kapasitas sampai dengan 256 member dalam satu group (WhatsApp.com, 2015).

Kemudian yang kedua adalah konflik perbedaan pandangan dan idealisme dalam sebuah group chat WhatsApp. Hal ini menjadi sebuah obstacle dalam keharmonisan kelompok multikultur dalam ruang virtual. Terkadang sebuah group chat terbentuk bukan dari kesamaan kelompok sosial atau politik, mengakibatkan beberapa individu dengan berbagai latar belakang akan berkumpul menjadi satu dalam ruang virtual. Individu yang mendapat tugas dari komunitas, kantor, atau institusi untuk menyebarkan informasi tentang suatu program, akan memanfaatkan semua channel komunikasinya untuk mengirimkan pesan ke banyak orang, salah satunya melalui aplikasi WhatsApp.

Seperti yang diungkapkan Oemar Madri Bafadhal, individu saat ini sudah mulai memilah mana informasi yang dapat dikonsumsi, dan mana informasi yang tidak perlu dikonsumsi. Individu cenderung untuk memilih channel yang memiliki kesamaan pandangan dengan dirinya (Bafadhal, 2017). Apabila di dalam group chat lain di paparkan informasi yang berbeda pandangan dan idealisme, individu tertentu akan cenderung terganggu.
"Saya sangat terganggu dengan pemaksaan kehendak yang dilakukan oleh sebagian kelompok, yang mengatasnamakan kelompoknya mewakili agama tertentu. Apalagi jika yang di sebarkan adalah berita bohong, untuk mempengaruhi orang lain. Di zaman dengan teknologi yang maju seperti sekarang, informasi yang valid akan sangat mudah ditemukan.” (Annisa Widyotami, 2017)

Simbol-simbol yang digunakan untuk pengiriman pesan dalam ruang virtual belum disepakati oleh anggota yang memiliki perbedaan latar belakang. Dalam teori interaksi simbolik, sebuah kata yang hanya berupa bunyi, tidak memiliki makna sampai sekelompok individu memiliki kesepakatan makna dari kata tersebut. Di ruang virtual anggota kelompok tidak bisa memberikan makna pada suatu simbol sampai ada kesepakatan makna oleh semua anggota kelompok juga tentunya. Misalnya jika anggota kelompok menuliskan "Umat Islam pro capres $X$ " tentunya anggota kelompok lain berhak untuk mendapatkan konfirmasi karena setiap individu memiliki pandangan sendiri.

Yang ketiga adalah konflik kesalahpahaman dalam menerima kalimat tanpa intonasi dan tinggi rendahnya nada suara, yang biasa diterima dalam komunikasi tatap muka. Hayatin Nusur, informan keenam, menceritakan dalam komunikasi teks dalam group chat WhatsApp, sering merasa tersinggung dengan rekan kerjanya. Karena kalimat atau kata yang dikirimkan menimbulkan efek kurang baik. Satu contoh dalam group chat Hayatin menemukan kata "Cepet dong" padahal jika diucapkan oleh rekan kerjanya, tidak bernada perintah atau ketus, namun karena tidak adanya intonasi yang menyertai pesan tersebut, maka dimaknai sebagai kalimat perintah. 


\section{Teori Computer-Mediated Communi-} cation menjelaskan untuk menyampaikan pesan nonverbal yang didapatkan pada komunikasi yang termediasi, diperlukan bahasa universal yang dimengerti oleh setiap individu, dan tentunya maknanya disepakati bersama oleh semua pengguna.

Emoticon atau emoji dapat digunakan sebagai substitusi pesan nonverbal. Emoticon adalah suatu simbol yang menggambarkan perasaan atau pun ekspresi dari pengirim pesan. Sejarah emoticon cukup panjang. Emoticon pertama kali ditemukan dalam naskah pidato Abraham Lincoln, berupa simbol ";)". Kemudian emoticon dikenal sangat luas ketika dikembangkan oleh instant messaging Yahoo! Messenger, dimana hanya mengetik =)) kemudian yang muncul dalam chat adalah simbol emoticon tertawa sambil berguling-guling (viva.co.id, 2011).

Pengguna aplikasi chat menggunakan bahasa slang, atau singkatan-singkatan seperti
LOL (laugh of loud), ROTFL (Rolling of the floor laughing), Ahahahaha (tertawa), dan sebagian dalam mengungkapkan pesan nonverbal. Seiring perkembangan emoticon yang diperkenalkan di perangkat IOS Apple dan tersedia juga secara eksklusif di aplikasi WhatsApp, masyarakat lebih memilih untuk menggunakan emoticon dalam memberikan simbol nonverbal dalam komunikasi yang menggunakan pesan teks (Liputan6.com, 2015).

Gambar 2 memperlihatkan data penelitian bahwa penggunaan emoticon naik $45 \%$ dan menggantikan bahasa slang yang sering digunakan oleh pengguna aplikasi kirim pesan seperti WhatsApp. Hal ini diperlukan untuk dapat memberikan informasi tambahan kepada penerima pesan, terkait pesan nonverbal yang dapat mengkonfirmasi pesan teks yang dikirimkan (Liputan6.com, 2015).

Walaupun WhatsApp sudah memberikan fitur emoji/emoticon dalam usahanya untuk

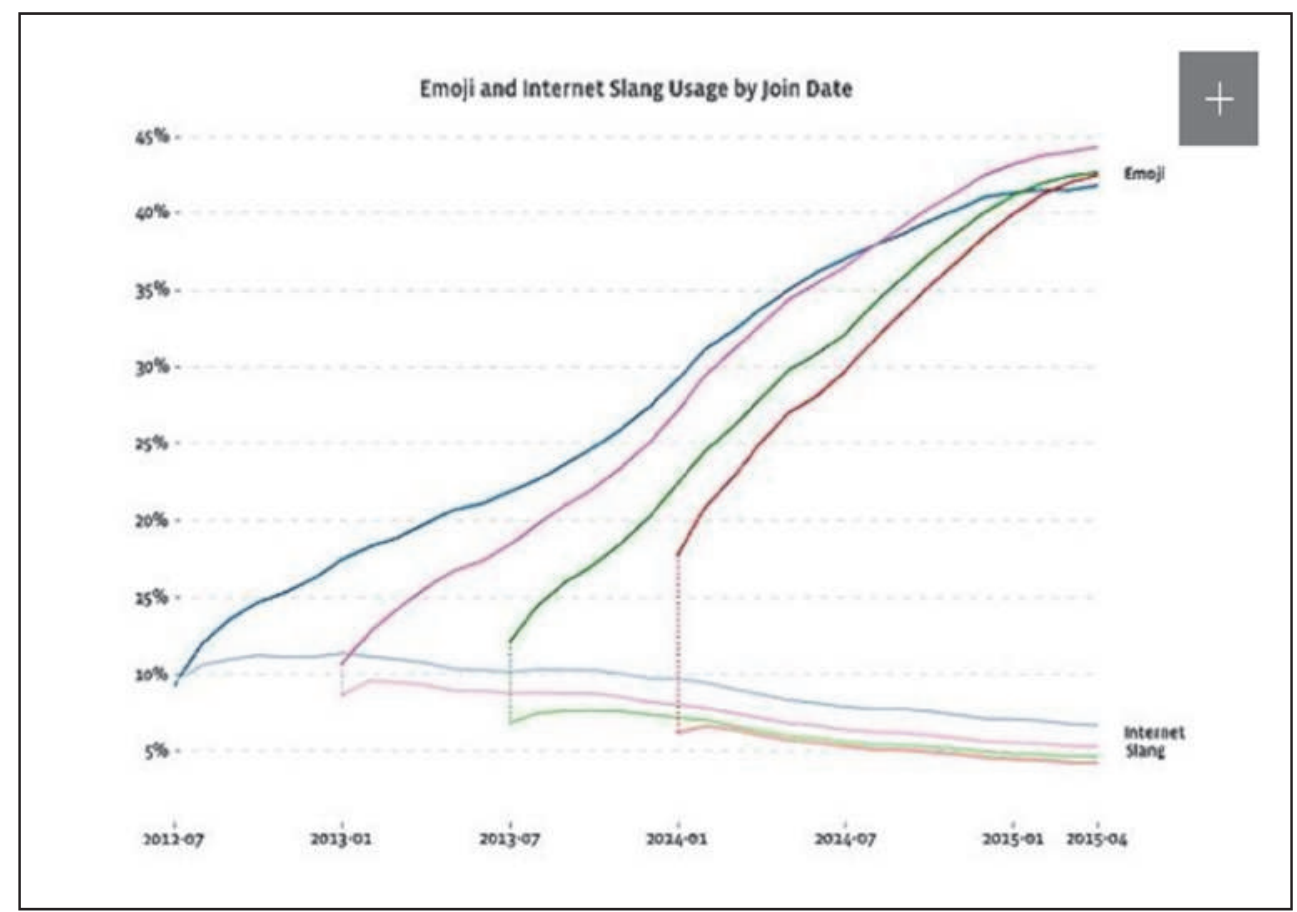

Gambar 2. Emoji and internet slang usage by join date

Sumber: http://tekno.liputan6.com/read/2229958/emoji-jadi-bahasa-slang-di-internet 
memberikan kelengkapan pesan verbal yang dikirimkan, tetap saja pengguna kadang lalai dalam penggunaannya. Hal ini disebabkan karena pengiriman pesan yang dikirim secara terburu-buru dan emosional yang berpotensi konflik dalam sebuah percakapan di group chat (Detik.com, 2017).

Terlebih lagi Bahasa Indonesia adalah bahasa yang memiliki banyak arti dan struktur yang berbeda dengan Bahasa Inggris. Hal ini terbukti dengan Bahasa Indonesia yang termasuk dalam daftar Bahasa yang relatif sulit untuk dipelajari (Tribunnews. com, 2017). Maka perlunya kecakapan dalam berkomunikasi multi kultur, baik saat pengiriman pesan, maupun menerima pesan.

"Leave group WhatsApp kini dianggap sebagai simbol pemutusan tali silaturahmi dalam suatu komunitas. Terkadang seberapa pun buruknya materi perbincangan dalam suatu group chat komunitas, masih akan tetap dipertahankan untuk bisa terus berada dalam grup tersebut. Beruntung WhatsApp memiliki fitur mute dan custom notification, dimana setiap message yang masuk, tidak perlu menggunakan notifikasi suara dan getaran, jadi pengguna tidak akan terganggu. Jika pada zaman sebelum digital, pemutusan tali silaturahmi bisa berbentuk walk out dari kedai kopi atau tempat berkumpul, maka di era digital ini pemutusan tali silaturahmi bisa berbentuk unfollow akun sosial media, block akun, dan leave group chat." (Indra Raharjo, 2017)

Group chat WhatsApp yang semula bertujuan untuk menjalin silaturahmi antar sekelompok individu dalam komunitas dari berbagai macam kultur akhirnya menjadi percikan konflik yang berpotensi, memutuskan hubungan komunikasi antar orang-orang didalam suatu komunitas. Keputusan seseorang untuk leave group chat disimpulkan sebagai simbol dari kemarahan seorang individu dari apa yang dialami dalam suatu aktivitas dalam ruang virtual group chat.

\section{Model Komunikasi di Ruang Virtual WhatsApp}

Setiap individu yang tergabung didalam ruang virtual WhatsApp memiliki tujuan yang sama, yaitu berinteraksi dengan rekan kerja, keluarga, maupun teman lama. Group chat dibuat untuk mempermudah interaksi dengan banyak orang.

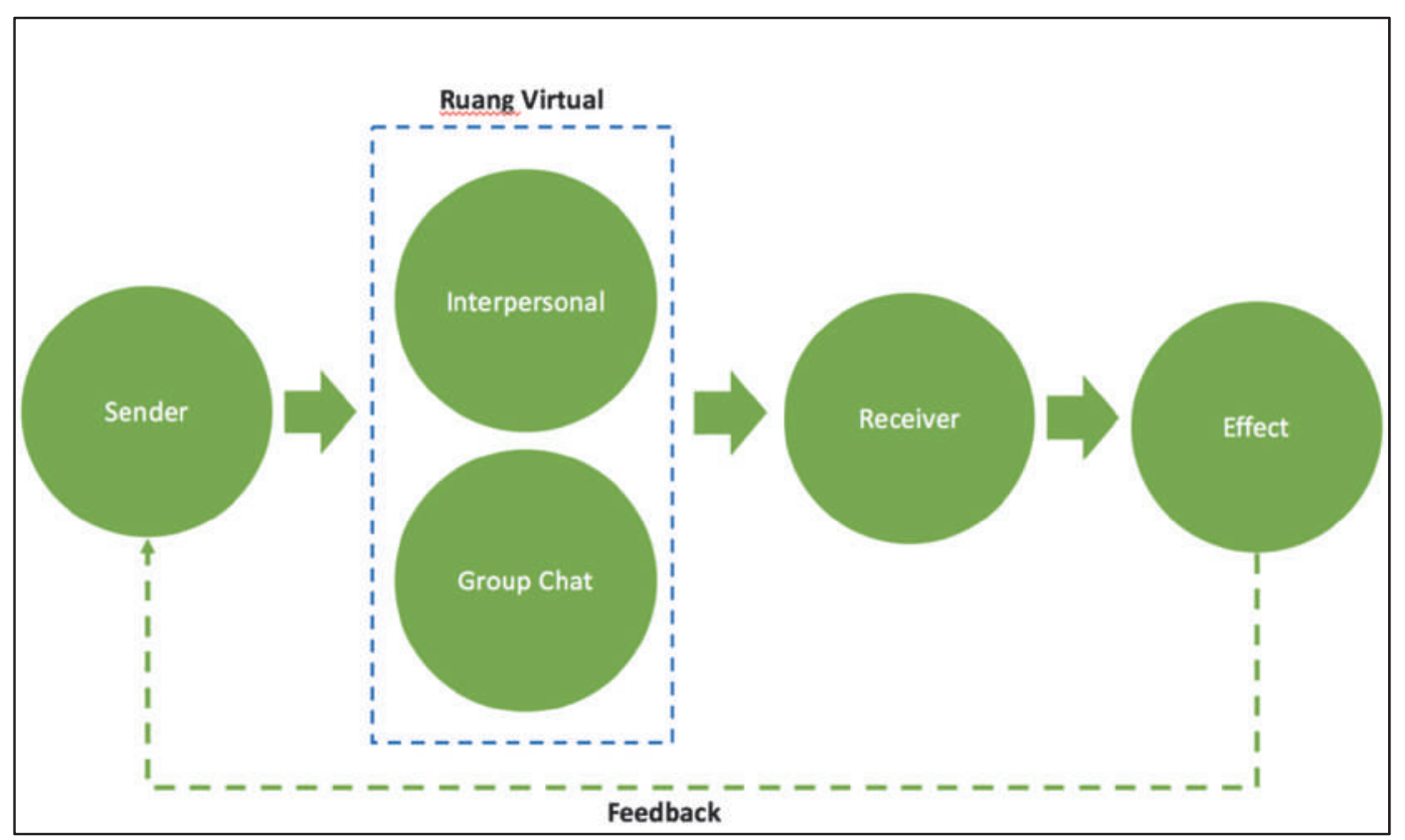

Gambar 3. Model interaksimulti kultur dalam ruang virtual WhatsApp Sumber : Data peneliti 2019 
Group chat memudahkan sekelompok individu berinteraksi kepada individu lain. Individu perlu mengetahui bahwa anggota yang berada didalam group chat berasal dari berbagai macam kultur. Pemaknaan tentang suatu pesan bisa sangat berbeda dengan anggota yang lainnya. Oleh karena itu biasanya group chat dibentuk dengan semangat kesamaan referensi dan persepsi, misalnya sama-sama berasal dari kampunghalaman yang sama.

Apabila group chat dibentuk hanya dengan kesamaan domisili, sekolah, kelompok kerja, dan lain-lain maka akan makin banyak perbedaan-perbedaan yang muncul dalam satu kelompok group chat.

Penelitianiniberhasilmenemukan model komunikasi yang terjadi pada ruang virtual WhatsApp. Ketika sender mengirimkan pesan melalui kanal ruang virtual, terdapat dua pilihan, langsung kepada individu yang dituju (jalur pribadi) atau melalui group chat yang berisi banyak individu multi kultur.

Jika pesan yang dikirimkan berpotensi memunculkan berbagai persepsi, maka efek yang akan ditimbulkan oleh receiver berbagai macam berdasarkan dari pemaknaan pesan dari setiap individu. Pemaknaan pesan sendiri bisa positif dan negatif. Pada penerimaan pesan dengan persepsi negatif, individu yang memiliki kecenderungan untuk berkonfrontasi akan langsung memberikan feedback di dalam ruang virtual group chat. Pengirim akan mendapatkanfeedback langsung. Sedangkan individu yang tidak suka berkonfrontasi lebih memilih untuk langsung leave group. Leave group juga dapat dimaknai sebagai pengiriman feedback kepada sender. Leave group bermakna kemarahan seorang individu terhadap suatu pesan yang diterima.

\section{Simpulan}

Penelitian ini menggambarkan fenomena yang terjadi dalam komunikasi pada ruang virtual berbentuk group chat melalui aplikasi WhatsApp yang dikaitkan pada hubungan antarpribadi. Teknologi digital yang diciptakan bertujuan untuk memudahkan komunikasi antar individu, yang dibatasi oleh batas-batas geografis. Interaksi antar individu diharapkan meningkat dari impersonal menjadi interpersonal, dengan mediasi perangkat smartphone.

Peneliti menemukan model interaksi multi kultur dalam ruang virtual yang menggambarkan dalam proses komunikasi ruang virtual terdapat distorsi yang disebabkan perbedaan pemaknaan dan juga cara mengirimkan simbol-simbol pesan. Mispersepsi yang terjadi dapat di reduksi dengan kecakapan dan literasi komunikasi multi kultur pada setiap pengguna.

Keberadaan aplikasi WhatsApp seharusnya dapat membatu interaksi komunikasi yang terjadi antar individu, namun percakapan yang terjadi cenderung mencederai individu lain. Arah hubungan dari nonintimate menjadi intimate tidak terjadi dengan baik. Individu cenderung seenaknya dalam mengirimkan pesan, tanpa memperdulikan efek yang akan timbul dari pesan yang dikirimkan.

Ini menandakan adanya kelemahan individu, dalam literasi komunikasi multi kultur pada ruang virtual WhatsApp. Substansi penelitian ini adalah pembelajaran untuk setiap individu mengenai interaksi multi kultur dalam ruang virtual menggunakan 
aplikasi WhatsApp, dimana setiap pesan yang dikirimkan dapat menimbulkan multi persepsi, terutama di ruang virtual yang memiliki banyak member dari berbagai latar belakang budaya.

Jika miskomunikasi sering terjadi pada face-to-face communication, seharusnya komunikasi yang memiliki delay waktu melalui WhatsApp dapat diminimalisir. Karena setiap pesan yang diketik dan akan dikirimkan, dapat dipikirkan terlebih dahulu efek yang akan timbul dari persepsi member lain, sebelum menekan tombol send. Penggunaan emoticon dapat membantu mengurangi multi persepsi yang akan muncul, jika kalimat yang dikirimkan memiliki potensi memunculkan konflik.

\section{Daftar Pustaka}

Amna, A. (2018). WhatsApp dan Konsep Jarak Sosial Baru di Masyarakat. ExposeJurnal Ilmu Komunikasi, 1(No.2).

Bafadhal, O. M. (2017). Komunikasi Ritual Penggunaan Aplikasi WhatsApp: Studi Konsumsi Berita Lewat Group WhatsApp. Jurnal Komunikasi Indonesia, V(1).

Detik.com. (2017). Etika di Grup WhatsApp Agar Tak Menyebalkan. Retrieved from https://inet.detik.com/ cyberlife/d-3559843/etika-di-grupWhatsApp-agar-tak-menyebalkan

Fauzi, R. (2017). Perubahan Budaya Komunikasi Pada Pengguna WhatsApp Di Era Media Baru. Jurnal Ilmu Komunikasi Efek, 1(No.1).

Griffin, E. (2012). A First Look At Communication Theory (Eight Edit). New York: McGraw-Hill.
Knapp, M. L., \& Hall, J. A. (1997). Nonverbal Communication in Human Interaction. Toronto: Thomson Wadsworth.

Kompas.com. (2014). CEO WhatsApp, dari Tukang Sapu Jadi Miliarder.

Liputan6.com. (2015). Emoji Jadi Bahasa Slang di Internet.

Nasrudin, D. (2017). Informan Interview Didin Nasrudin. Jakarta.

Nasrullah, R. (2017). Etnografi Virtual. Bandung: Simbiosa Rekatama Media.

Silvana, H. (2013). Komunikasi Antarbudaya Dalam Masyarakat Multikultur. Jurnal Kajian Komunikasi, 1(No.1, Juni 2013).

Simangunsong, B. A. (2016). Interaksi Antarmanusia Melalui Media Sosial Facebook Mengenai Topik Keagamaan. Aspikom, 3 (1).

Similarweb.com. (2017). Apps.

Soedarsono, D. K. (2017). Model Komunikasi Teman Sebaya Dalam Pembentukan Identitas Diri Remaja Global Melalui Media Internet. Aspikom.

Tribunnews.com. (2017). 10 Bahasa yang Paling Sulit Dipelajari di Dunia, Jangan Kaget, Bahasa Indonesia Ada dalam Daftar Ini.

Walther, J. B. (1996). Computer-Mediated Communication: Impersonal, Interpersonal, and Hyperpersonal Interaction. Communication Research.

WhatsApp. (2015). About WhatsApp.

Wired.com. (2018). The inside story of Jan Koum and how Facebook bought WhatsApp. Retrieved from https://www. wired.co.uk/article/whats-app-ownerfounder-jan-koum-facebook 